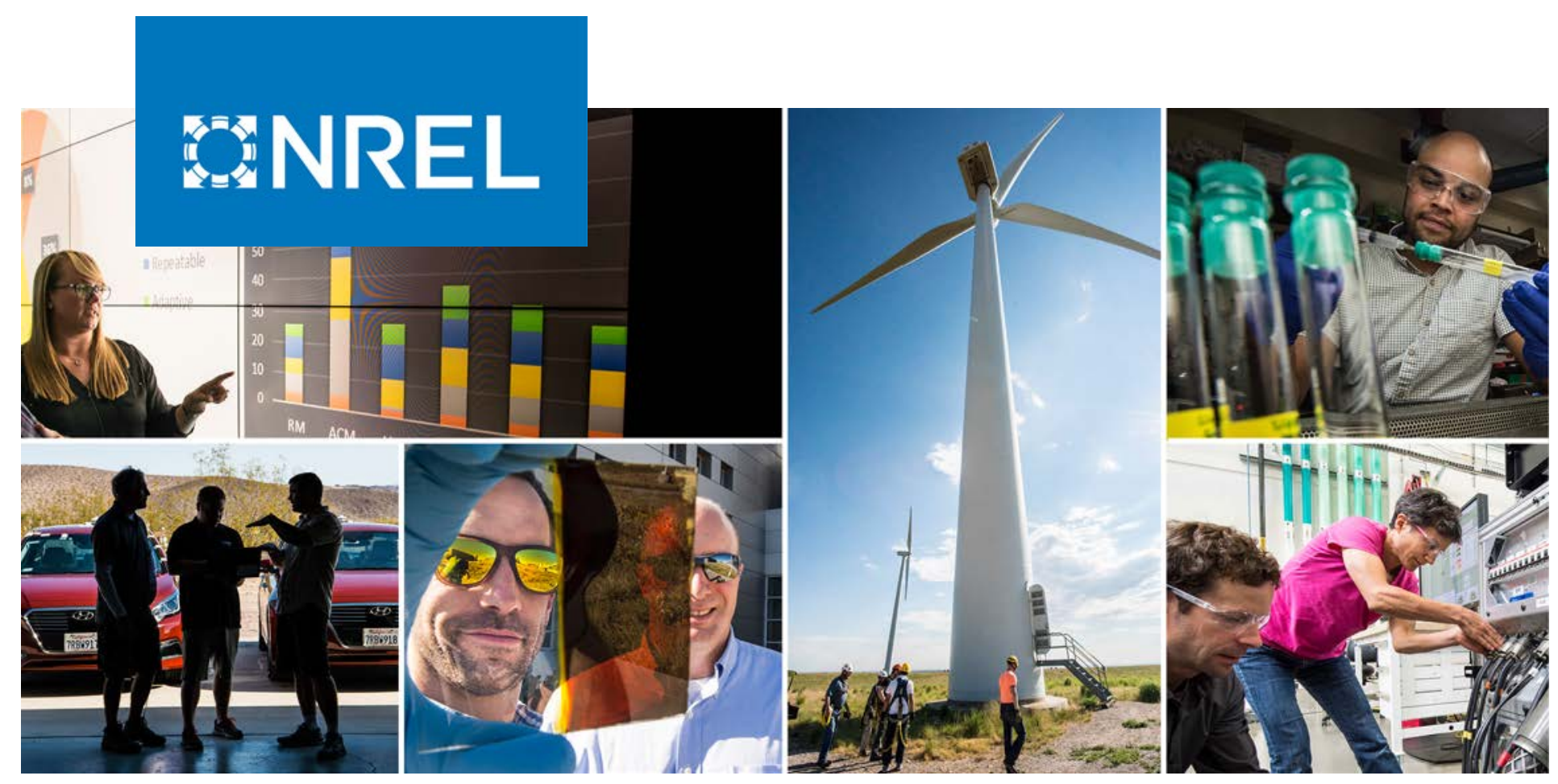

\title{
A Procedure to Correct the Historical Atmospheric Longwave Irradiance Data When the World Reference Is Established with Respect to the International System of Units
}

Ibrahim Reda, Afshin Andreas, and Peter Gotseff

National Renewable Energy Laboratory

NREL is a national laboratory of the U.S. Department of Energy Office of Energy Efficiency \& Renewable Energy

Operated by the Alliance for Sustainable Energy, LLC

This report is available at no cost from the National Renewable Energy Laboratory (NREL) at www.nrel.gov/publications.
Technical Report

NREL/TP-1900-81862

January 2022 


\section{ENREL}

\section{A Procedure to Correct the Historical Atmospheric Longwave Irradiance Data When the World Reference Is Established with Respect to the International System of Units}

Ibrahim Reda, Afshin Andreas, and Peter Gotseff

National Renewable Energy Laboratory

\section{Suggested Citation}

Reda, Ibrahim, Afshin Andreas, and Peter Gotseff. 2022. A Procedure to Correct the Historical Atmospheric Longwave Irradiance Data When the World Reference Is Established with Respect to the International System of Units. Golden, CO: National Renewable Energy Laboratory. NREL/TP-1900-81862.

https://www.nrel.gov/docs/fy22osti/81862.pdf.

NREL is a national laboratory of the U.S. Department of Energy Office of Energy Efficiency \& Renewable Energy Operated by the Alliance for Sustainable Energy, LLC

This report is available at no cost from the National Renewable Energy Laboratory (NREL) at www.nrel.gov/publications.

Contract No. DE-AC36-08GO28308
Technical Report

NREL/TP-1900-81862

January 2022

National Renewable Energy Laboratory 15013 Denver West Parkway Golden, CO 80401

303-275-3000 • www.nrel.gov 


\section{NOTICE}

This work was authored by the National Renewable Energy Laboratory, operated by Alliance for Sustainable Energy, LLC, for the U.S. Department of Energy (DOE) under Contract No. DE-AC36-08GO28308. Funding provided by NREL Metrology Laboratory. The views expressed herein do not necessarily represent the views of the DOE or the U.S. Government.

This report is available at no cost from the National Renewable Energy Laboratory (NREL) at www.nrel.gov/publications.

U.S. Department of Energy (DOE) reports produced after 1991 and a growing number of pre-1991 documents are available free via www.OSTI.gov.

Cover Photos by Dennis Schroeder: (clockwise, left to right) NREL 51934, NREL 45897, NREL 42160, NREL 45891, NREL 48097, NREL 46526.

NREL prints on paper that contains recycled content. 


\section{Acknowledgments}

This work was supported by the U.S. Department of Energy Office of Energy Efficiency and Renewable Energy (Contract No. DE-AC36-99-GO10337) and the Atmospheric Radiation Measurement program (Interagency Work Order 353925-A-Q1). Additionally, we thank National Renewable Energy Laboratory (NREL) staff members Martina Stoddard and Mark Kutchenreiter, who helped to ensure the quality of the outdoor data at NREL; and Julian Gröbner, from the Physikalisch-Meteorologisches Observatorium Davos, for continuously sharing ideas about such a challenging subject. 


\section{List of Acronyms}

ACP

ARM

DOE

IRIS

NREL

PIR

PMOD

SGP

SI

WISG absolute cavity pyrgeometer

Atmospheric Radiation Measurement

U.S. Department of Energy

infrared reference integrating sphere

National Renewable Energy Laboratory

precision infrared radiometer

Physikalisch-Meteorologisches Observatorium Davos

Southern Great Plains

International System of Units

World Infrared Standard Group 


\section{Table of Contents}

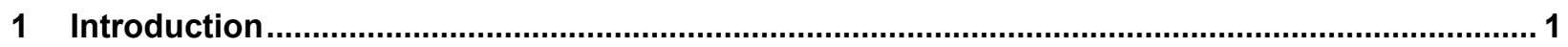

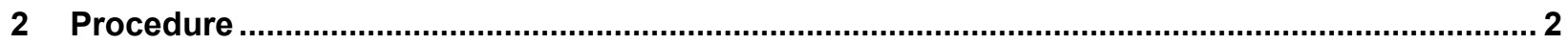

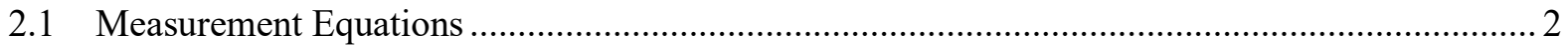

2.1.1 National Renewable Energy Laboratory Equation................................................... 2

2.1.2 Physikalisch-Meteorologisches Observatorium Davos Equation ..................................2

2.2 Step-by-Step Procedure for Each Site _..................................................................................... 3

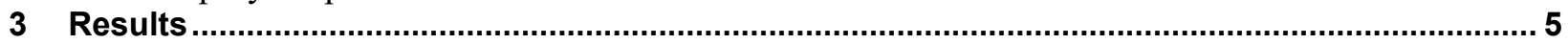

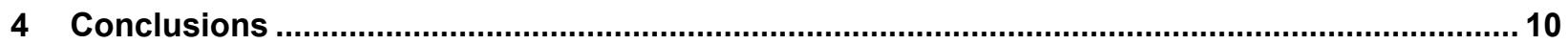

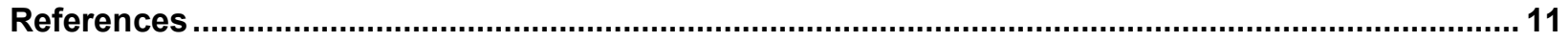




\section{List of Figures}

Figure 1. Corrected $W_{\text {net }}$ PIR at NREL from September 14, 2019, to August 8, 2021 ........................... 6

Figure 2. Precipitable water [mm] at NREL from September 14, 2019, to August 8, 2021 .................... 6

Figure 3. Corrected $\mathrm{W}_{\text {atm }}$ PIR at NREL from September 14, 2019, to August 8, 2021 .......................... 6

Figure 4. PIR at NREL corrected $\mathrm{W}_{\text {net }}$ versus the $\mathrm{W}_{\text {net }}$ correction....................................................... 7

Figure 5. CG4 at NREL corrected $\mathrm{W}_{\text {net }}$ versus the $\mathrm{W}_{\text {net }}$ correction........................................................ 7

Figure 6. Corrected $\mathrm{W}_{\text {net }}$ PIR at the SGP station sgpsirsS01 from June 16, 2020, to July 14, 2021 ........... 7

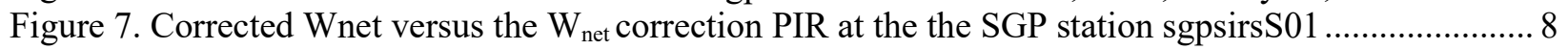

Figure 8. Coorrected $W_{\text {net }}$ PIR at the SGP station sgpsirsE13 from June 16, 2020, to July 14, $2021 \ldots \ldots \ldots . .8$

Figure 9. Corrected $\mathrm{W}_{\text {net }}$ versus the $\mathrm{W}_{\text {net }}$ correction PIR at the SGP station sgpsirsE13 …..................... 8

Figure 10. Corrected $\mathrm{W}_{\text {net }}$ PIR at the SGP station sgpbrsC1 from June 16, 2020, to July 14, 2021 .......... 9

Figure 11. Corrected $\mathrm{W}_{\text {net }}$ versus the $\mathrm{W}_{\text {net }}$ correction PIR at the $\mathrm{SGP}$ station sgpbrsC1 ......................... 9

\section{List of Tables}

Table 1. 


\section{Introduction}

Historical atmospheric longwave irradiance data sets with traceability to the International System of Units (SI) are essential for renewable energy and atmospheric science research and applications. To date, all pyrgeometers used to measure the irradiance are traceable to the interim World Infrared Standard Group (WISG), not to SI units. In 2013, the Absolute Cavity Pyrgeometer (ACP) (Reda et al. 2012) was developed at the National Renewable Energy Laboratory (NREL) to measure the atmospheric longwave irradiance. The ACP has been compared against the InfraRed Integrating Sphere (IRIS), developed by the PhysikalischMeteorologisches Observatorium Davos/World Radiation Center (PMOD/WRC) (Gröbner 2012). The ACP and the IRIS are absolute instruments traceable to SI units through the International Temperature Scale of 1990. Results of six comparisons between the ACP and the IRIS at different locations have shown that the irradiance measured by WISG pyrgeometers underestimates clear-sky atmospheric longwave irradiance by $2 \mathrm{~W} / \mathrm{m}^{2}$ to $6 \mathrm{~W} / \mathrm{m}^{2}$ (Gröbner et al. 2014); therefore, once the world reference is established with traceability to SI units, the WISG would be corrected, then used to calibrate field pyrgeometers with traceability to SI units.

The following described method is used to correct the historical atmospheric longwave irradiance data sets in anticipation of the WISG scale change. 


\section{Procedure}

\subsection{Measurement Equations}

\subsubsection{National Renewable Energy Laboratory Equation}

From Reda et al. (2002):

$$
W_{a t m}=K_{1} V+K_{2} W_{r}+K_{3}\left(W_{d}-W_{r}\right)
$$

where:

- $\mathrm{W}_{\mathrm{atm}}$ is the atmospheric longwave radiation in $\mathrm{W} / \mathrm{m}^{2}$.

- $\mathrm{K}_{2}$ and $\mathrm{K}_{3}$ are the calibration coefficients of the pyrgeometer, calibrated at the PMOD.

- $\mathrm{K}_{1}$ is the reciprocal of the pyrgeometer's responsivity, calculated from the outdoor calibration described below.

- $\mathrm{V}$ is the pyrgeometer thermopile output, in microvolts.

- $\mathrm{W}_{\mathrm{r}}$ is the pyrgeometer receiver radiation $=\sigma * \mathrm{~T}_{\mathrm{r}}^{4}$, and $\mathrm{T}_{\mathrm{r}}=\mathrm{T}_{\mathrm{c}}+\mathrm{K}_{4} * \mathrm{~V}$, where:

$\circ \quad \sigma$ is Stefan-Boltzman constant $=5.6704 * 10^{-8} \mathrm{~W} / \mathrm{m}^{2} / \mathrm{K}^{4}$

$\circ \mathrm{T}_{\mathrm{c}}$ is the pyrgeometer case temperature, in Kelvin.

$\circ \mathrm{S}$ is the Seebeck coefficient $=39 \mathrm{~V} / \mathrm{K}$.

$\circ \mathrm{n}$ is the number of thermopile junctions $=56$ junctions.

$\circ \quad \mathrm{E}$ is the thermopile efficiency factor $=0.65$.

- $\mathrm{K}_{4}$ is the thermopile efficiency factor equal to $1 /(\mathrm{S} * \mathrm{n} * \mathrm{E})=0.0007044 \mathrm{~K}_{\mathrm{uV}} \mathrm{uV}^{-1}$.

- $\mathrm{W}_{\mathrm{d}}$ is the pyrgeometer dome radiation $=\sigma^{*} \mathrm{~T}_{\mathrm{d}}^{4}$, where $\mathrm{T}_{\mathrm{d}}$ is the dome temperature in Kelvin.

Equation 1 is rewritten in the following form:

where:

$$
W_{\text {out }}=W_{a t m}-W_{\text {net }}=W_{a t m}-K_{1} V
$$

- $\mathrm{W}_{\text {net }}$ is the net irradiance measured by the pyrgeometer thermopile:

$$
W_{\text {net }}=-K_{1} V
$$

- $\mathrm{W}_{\text {out }}$ is the outgoing irradiance from the pyrgeometer:

$$
W_{\text {out }}=K_{2} W_{r}+K_{3}\left(W_{d}-W_{r}\right)
$$

\subsubsection{Physikalisch-Meteorologisches Observatorium Davos Equation} From Philipona, Fröhlich, and Ch. Betz (1995): 


$$
W_{a t m}=\frac{V}{C}\left(1+K_{1} \sigma T_{b}^{3}\right)+K_{2} W_{b}+K_{3}\left(W_{d}-W_{b}\right)
$$

where $\mathrm{C}$ is the pyrgeometer responsivity, and $\mathrm{T}_{\mathrm{b}}$ is the case temperature.

Similar to equations 2 and 3 :

$$
\begin{gathered}
W_{\text {net }}=\frac{V}{C}\left(1+K_{1} \sigma T_{b}^{3}\right) \\
W_{\text {out }}=K_{2} W_{b}+K_{3}\left(W_{d}-W_{b}\right)
\end{gathered}
$$

\subsection{Step-by-Step Procedure for Each Site}

1. Download the data for at least 2 years. Data include pyrgeometer serial number and calibration coefficients traceable to the WISG, $\mathrm{V}, \mathrm{T}_{\text {case }}$, and $\mathrm{T}_{\text {dome. }}$.

2. Calculate $\mathrm{W}_{\text {net }}$ using equation 3 or 6 .

3. Calculate the minimum and maximum values of $\mathrm{W}_{\text {net }}=$ Min and Max.

4. Choose a site where $\mathrm{W}_{\text {net }}$ is the smallest minimum value.

5. Define the new scale from $0 \mathrm{~W} / \mathrm{m}^{2}$ to $\mathrm{X} \mathrm{W} / \mathrm{m}^{2}$, where $\mathrm{X}$ is the consensus value approved by the World Meteorological Organization Commission for Instruments and Methods of Observation. Note that $0 \mathrm{~W} / \mathrm{m}^{2}$ represents cloudy-sky conditions, and $\mathrm{X} \mathrm{W} / \mathrm{m}^{2}$ represents clear-sky conditions and the lowest $\mathrm{W}_{\text {net }}$ at the NREL site.

6. Calculate the slope:

$$
S=\frac{\operatorname{Max}-\operatorname{Min}}{0-X}
$$

7. Calculate the $\mathrm{W}_{\text {net }}$ correction:

$$
Z=\frac{W_{n e t}}{S}
$$

8. Calculate the corrected $\mathrm{W}_{\text {net: }}$ :

$$
W_{\text {net }, \text { corr }}=W_{\text {net }}-Z
$$

9. Calculate the corrected $\mathrm{W}_{\mathrm{atm}}$ :

$$
W_{\text {atm,corr }}=W_{\text {net,corr }}+W_{\text {out }}
$$

10. Calculate the uncertainty of the irradiance measured by each pyrgeometer with respect to the SI units, U95:

$$
U_{95}=\sqrt{U_{r e f}^{2}+U_{\text {test }}^{2}}
$$


where:

$$
U_{r e f}=\sqrt{U_{A C P \& I R I S}^{2}+U_{W I S G}^{2}}
$$

The estimated values of $U_{\text {ACP\&IRIS }}= \pm 2 \mathrm{~W} / \mathrm{m}^{2}$ and $U_{\text {WISG }}= \pm 1 \mathrm{~W} / \mathrm{m}^{2}$; and $U_{\text {test }}$ is the calibration uncertainty of the pyrgeometer under test. 


\section{Results}

Historical data were downloaded from NREL's Solar Radiation Research Laboratory Baseline Measurement System and three U.S. Department of Energy (DOE) Atmospheric Radiation Measurement (ARM) program sites: sgpbrsC1, spgsirsE13, and sgpserisS01. In this method, $\mathrm{X}=$ $5 \mathrm{~W} / \mathrm{m}^{2}$ is used as an example to show the following results, the consensus value of $\mathrm{X}$ would be used once it is approved.

Table 1 includes sites and the pyrgeometers calibration coefficients: $U_{\text {test, }}$, slope, minimum $\mathrm{W}_{\text {net, }}$, and U95. NREL's slope is applied to the three DOE ARM sites because NREL is one of the international sites that has the lowest value of $\mathrm{W}_{\text {net. }}$.

Table 1.

\begin{tabular}{llllllllll}
\hline Site & Serial \# & k1 & k2 & k3 & k4= kr & $\mathbf{U}_{\text {test }}$ & slope & Wnet & $\mathbf{U}_{95}$ \\
\hline NREL & PIR31193F3 & 0.26317 & 1.0006 & -4 & $7.04 \mathrm{E}-04$ & 2.7 & 42.3 & -206.3 & 3.5 \\
NREL & CG410548 & 0.0737 & 1.0013 & 0 & $7.04 \mathrm{E}-04$ & 2.9 & 33.5 & -167.5 & 3.7 \\
sgpbrsC1 & PIR30695F3 & 0.24487 & 0.9968 & -3.6 & $7.04 \mathrm{E}-04$ & 3.1 & 42.3 & -141.2 & 3.8 \\
spgsirsE13 & PIR38870F3 & 0.26379 & 0.9942 & -4.6 & $7.04 \mathrm{E}-04$ & 3.0 & 42.3 & -147.4 & 3.7 \\
sgpserisS01 & PIR30689F3 & 0.25271 & 0.9963 & -3.6 & $7.04 \mathrm{E}-04$ & 3.1 & 42.3 & -84.7 & 3.8 \\
\hline
\end{tabular}

Figure 1 shows NREL's precision infrared radiometer (PIR) corrected $\mathrm{W}_{\text {net. }}$ Figure 2 shows the precipitable water content at NREL. Using descriptive statistics for the data set results in mean $=$ $10.56 \mathrm{~W} / \mathrm{m}^{2}$, standard error $=0.09 \mathrm{~W} / \mathrm{m}^{2}$, median $=9.4 \mathrm{~W} / \mathrm{m}^{2}$, and mode $=6.7 \mathrm{~W} / \mathrm{m}^{2}$. This implies that most of the time, the precipitable water content is larger than $10 \mathrm{~mm}$; therefore, the scale correction is required for all pyrgeometers deployed at NREL and the DOE ARM Southern Great Plains (SGP) sites (Gröbner et al. 2014).

Figures 3 and 4 show the correction of PIR $\mathrm{W}_{\text {atm }}$ and the corrected $\mathrm{W}_{\text {net }}$ versus $\mathrm{W}_{\text {net }}$ correction for all sky conditions. Figure 5 shows the $\mathrm{CG} 4$ corrected $\mathrm{W}_{\text {net }}$ versus the $\mathrm{W}_{\text {net }}$ correction. Figures 6 through 11 show the three SGP sites results using PIRs, the corrected $\mathrm{W}_{\text {net, }}$, and the corrected $\mathrm{W}_{\text {net }}$ versus $\mathrm{W}_{\text {net }}$ correction for all sky conditions. 


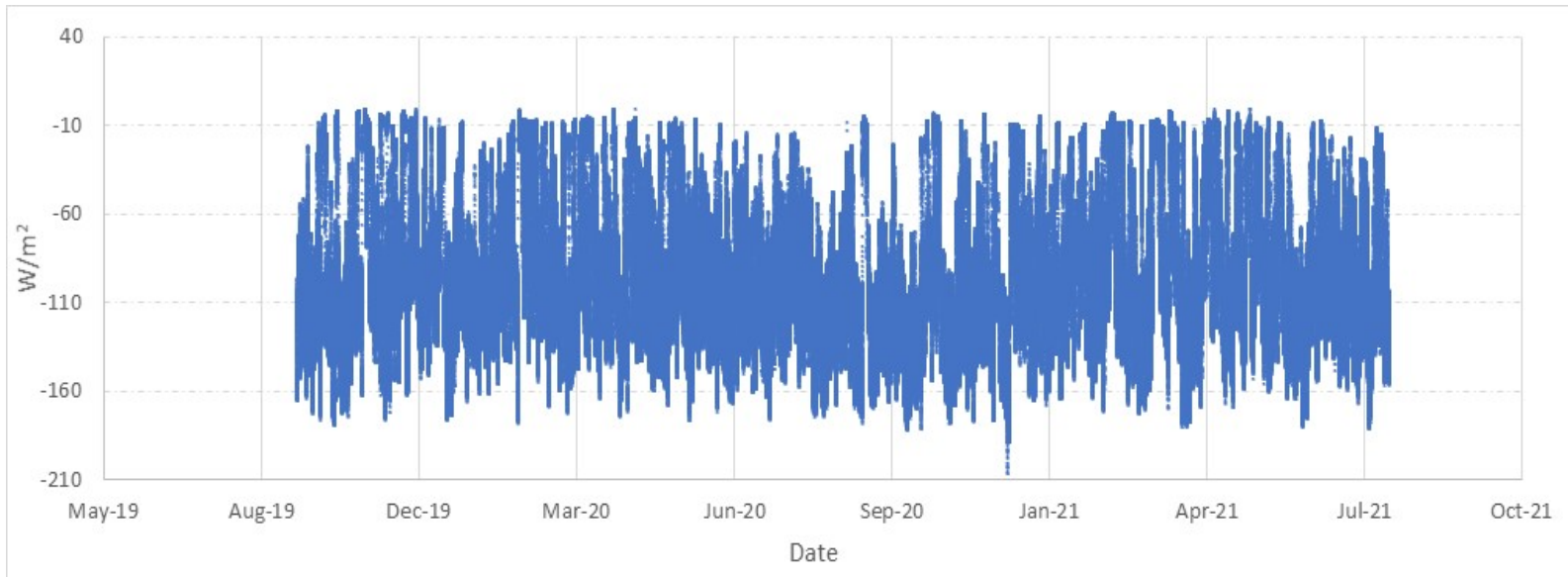

Figure 1. Corrected $W_{\text {net }}$ PIR at NREL from September 14, 2019, to August 8, 2021

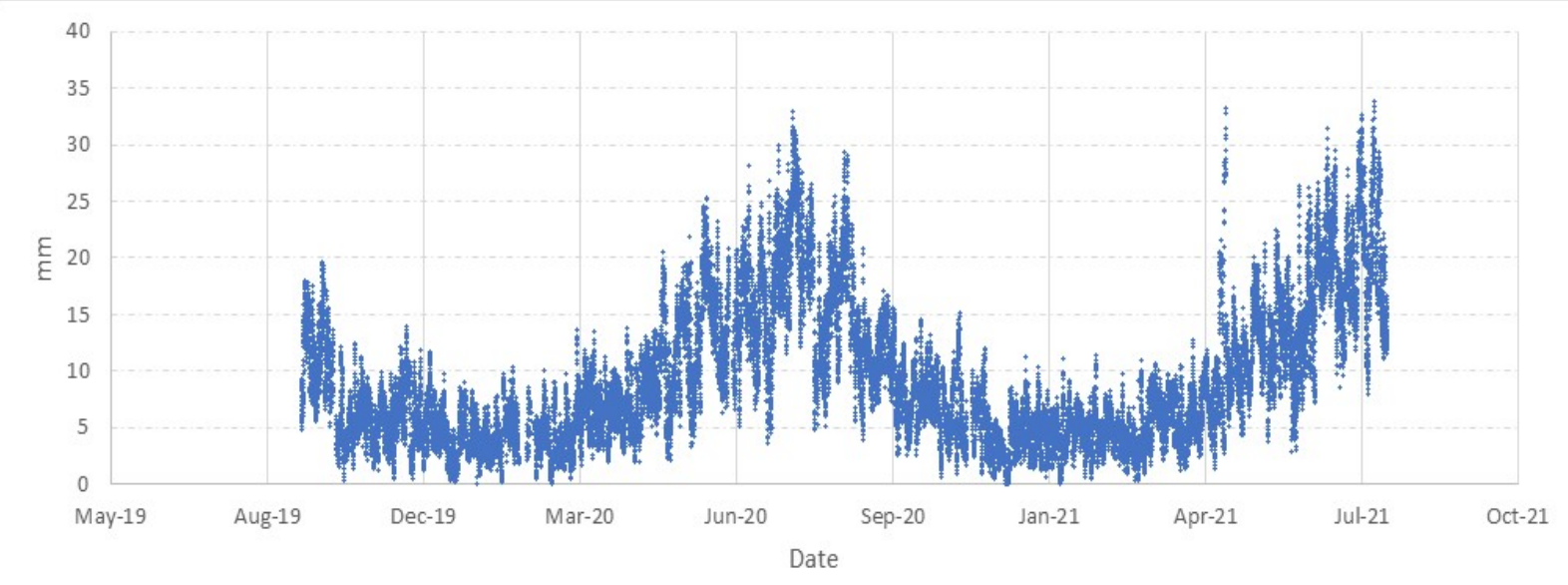

Figure 2. Precipitable water [mm] at NREL from September 14, 2019, to August 8, 2021

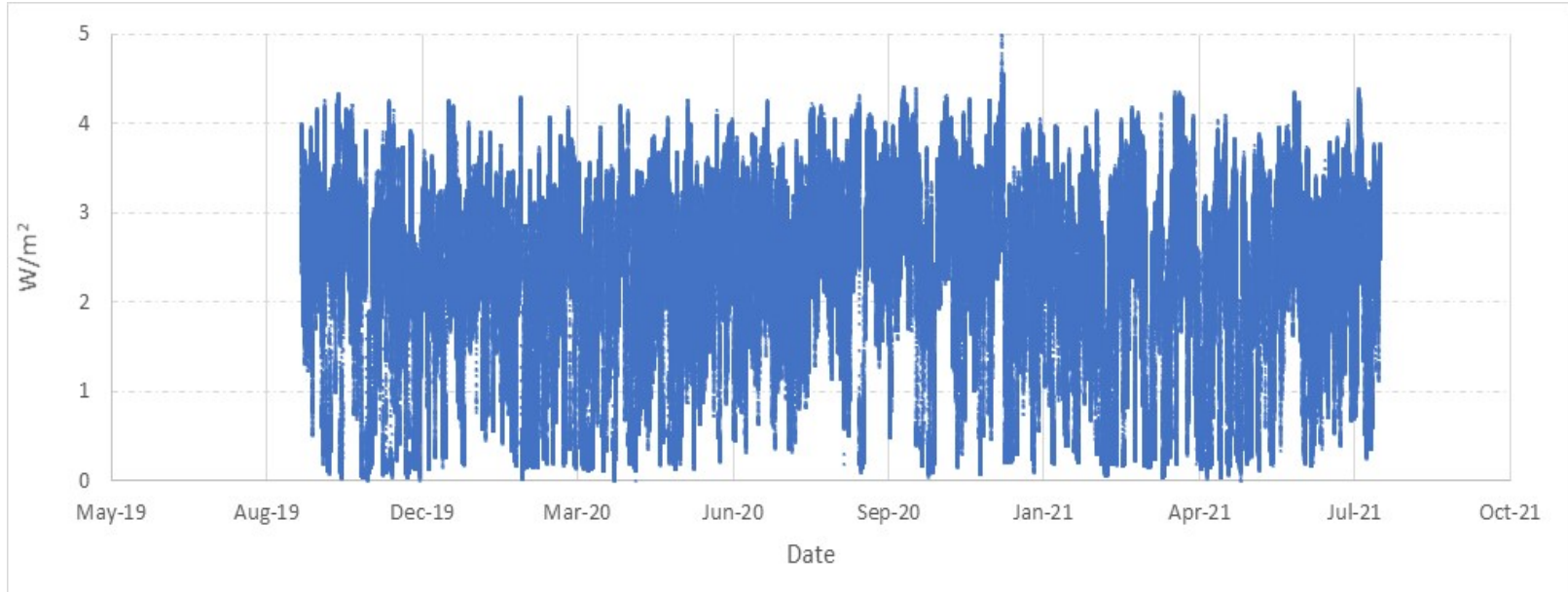

Figure 3. Corrected $\mathrm{W}_{\mathrm{atm}}$ PIR at NREL from September 14, 2019, to August 8, 2021 


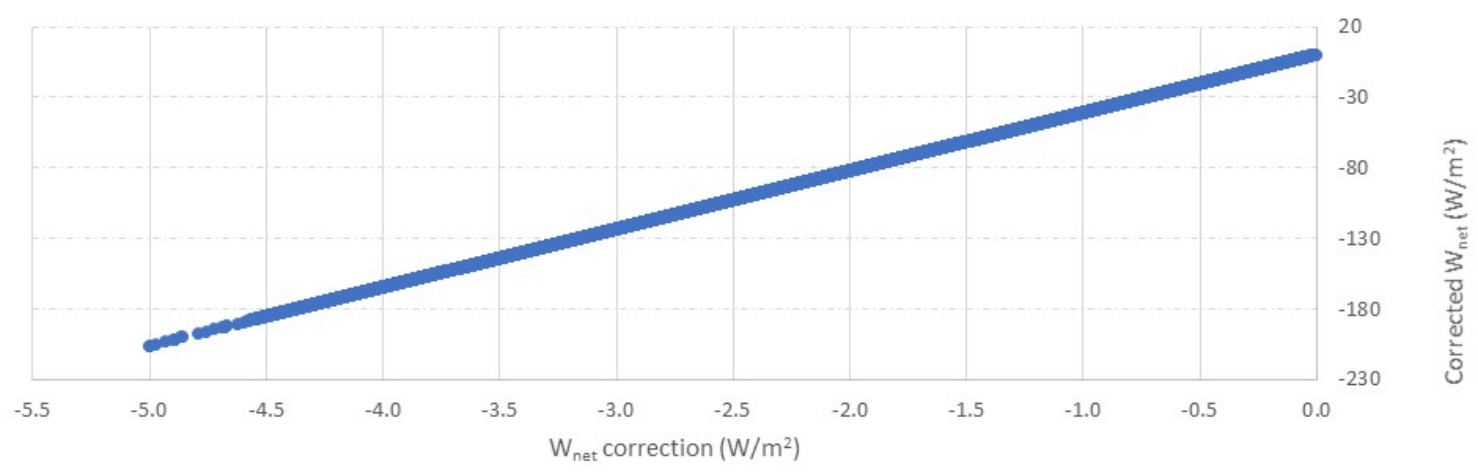

Figure 4. PIR at NREL corrected $\mathbf{W}_{\text {net }}$ versus the $\mathbf{W}_{\text {net }}$ correction

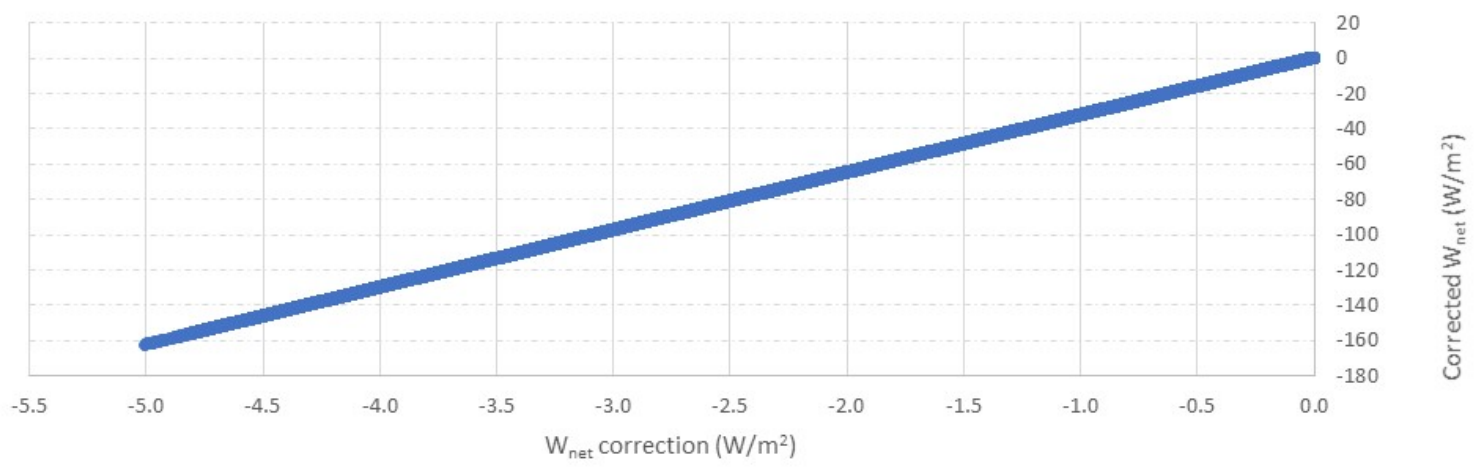

Figure 5. CG4 at NREL corrected $\mathbf{W}_{\text {net }}$ versus the $\mathbf{W}_{\text {net }}$ correction

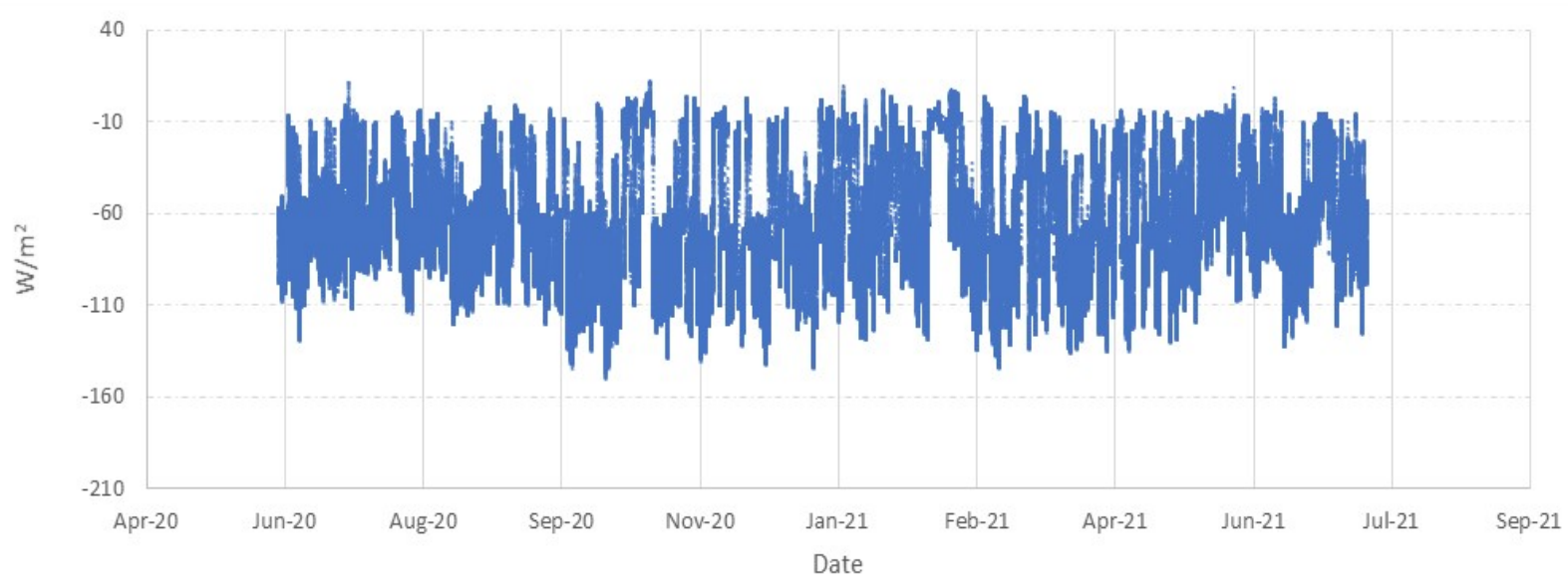

Figure 6. Corrected $W_{\text {net }}$ PIR at the SGP station sgpsirsS01 from June 16, 2020, to July 14, 2021 


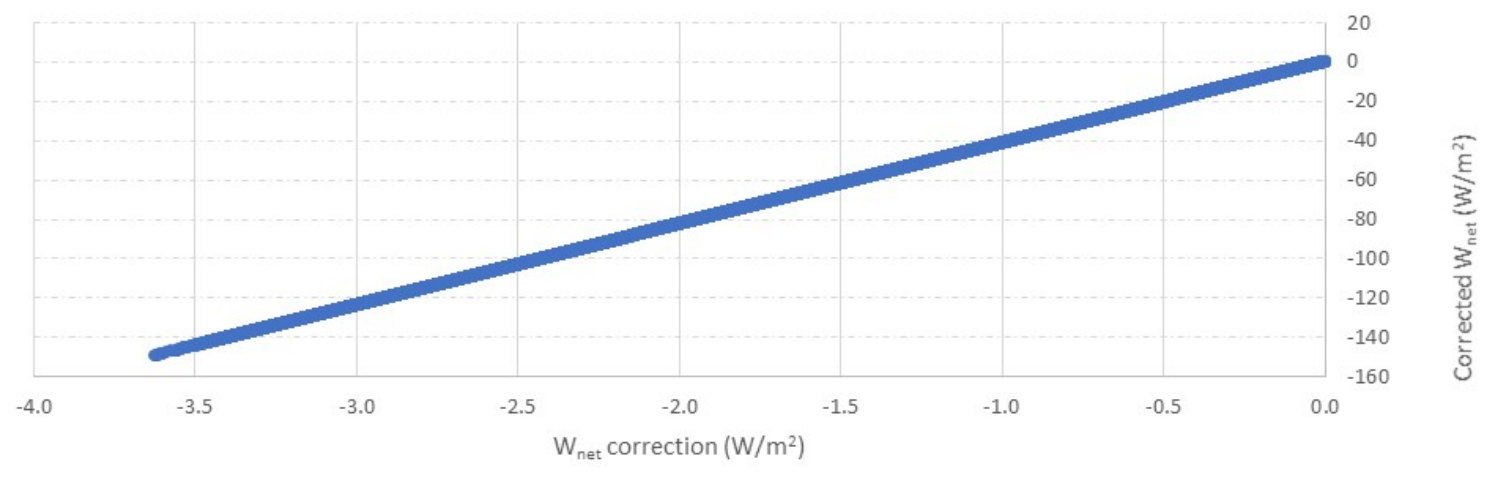

Figure 7. Corrected Wnet versus the $\mathbf{W}_{\text {net }}$ correction PIR at the the SGP station sgpsirsS01

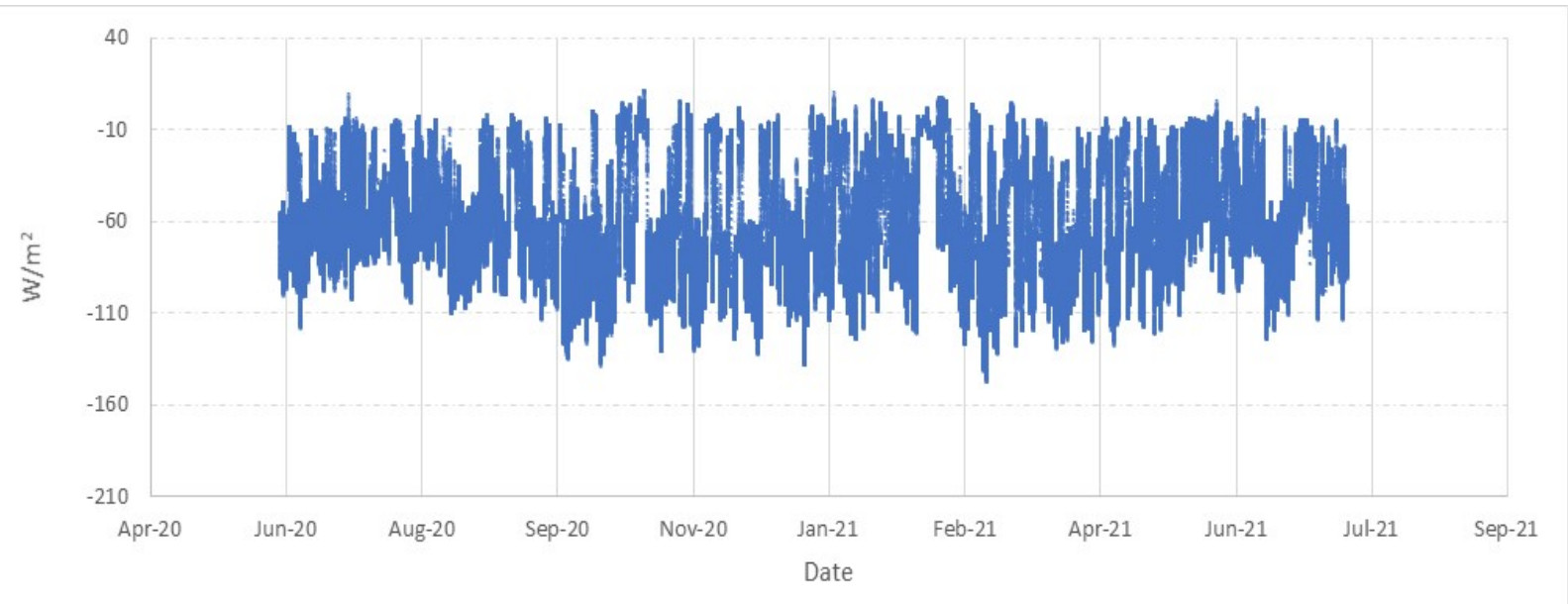

Figure 8. Coorrected $W_{\text {net }}$ PIR at the SGP station sgpsirsE13 from June 16, 2020, to July 14, 2021

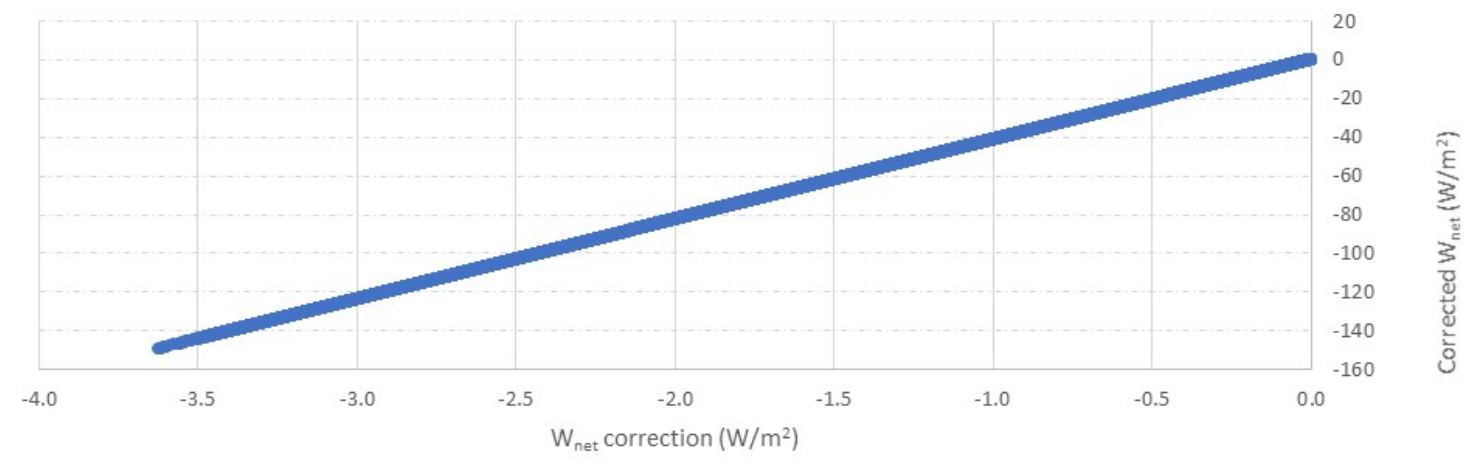

Figure 9. Corrected $W_{\text {net }}$ versus the $W_{\text {net }}$ correction PIR at the SGP station sgpsirsE13 


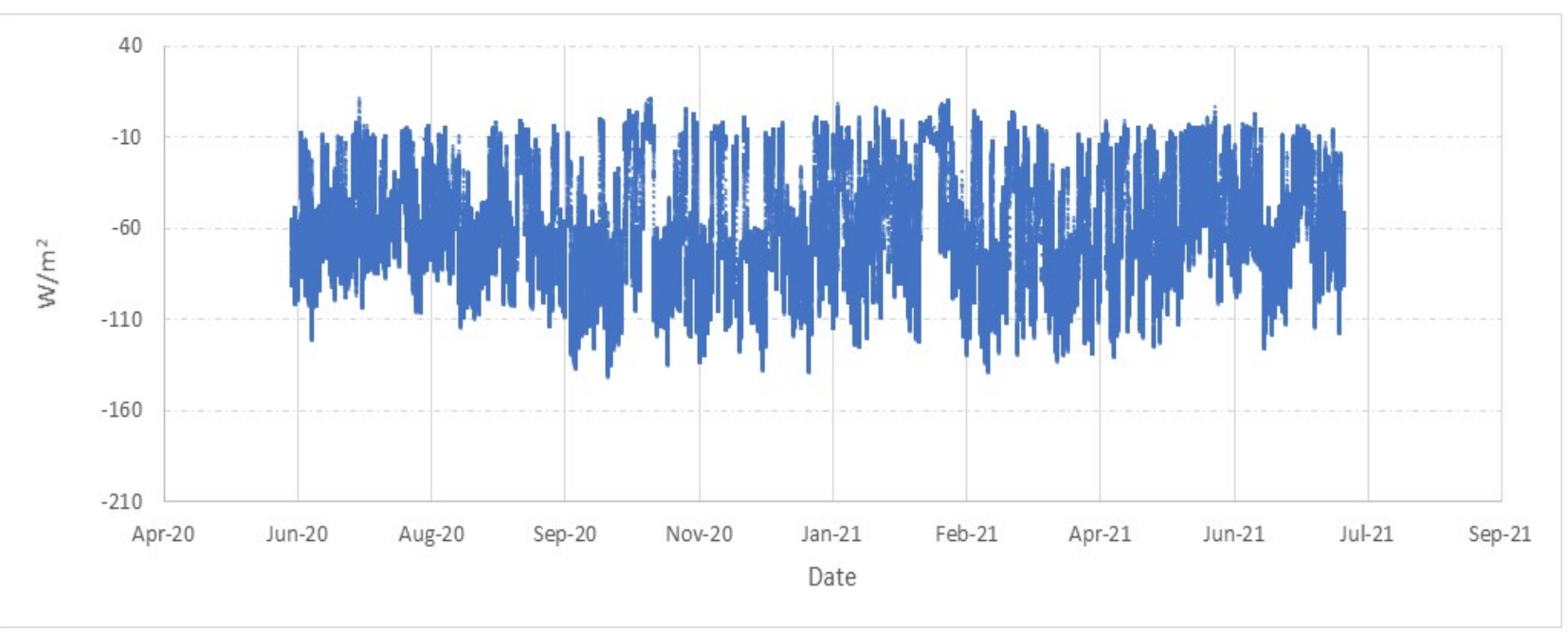

Figure 10. Corrected $W_{\text {net }}$ PIR at the SGP station sgpbrsC1 from June 16, 2020, to July 14, 2021

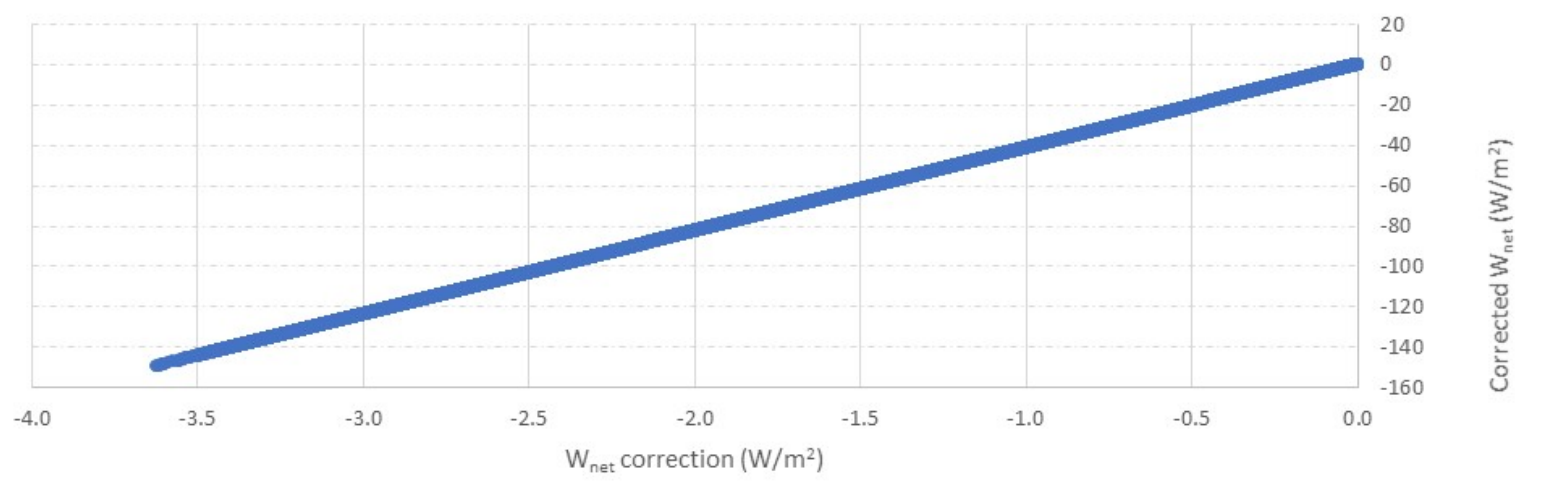

Figure 11. Corrected $W_{\text {net }}$ versus the $W_{\text {net }}$ correction PIR at the SGP station sgpbrsC1 


\section{Conclusions}

Based on the results, this procedure might be used to correct historical data measured by all pyrgeometers deployed in U.S. sites using the default slope, e.g., 42.3 for PIRs and 33.5 for CG4s. Once the international reference is established with traceability to the SI units, a larger data set for 5 years might be used to recalculate the default slope to account for all sky conditions at NREL and other international sites that have minimum $\mathrm{W}_{\text {net. }}$ To use this method, the pyrgeometer serial number and the calibration coefficients traceable to WISG, $\mathrm{V}, \mathrm{T}_{\text {case, }}$, and $\mathrm{T}_{\text {dome }}$ must be available to properly correct the data. For the Baseline Surface Radiation Network data set, it is recommended that in the future the data must include the pyrgeometer serial number and the calibration coefficients traceable to the WISG, $\mathrm{V}, \mathrm{T}_{\text {case, }}$, and $\mathrm{T}_{\text {dome }}$ to correct future data if the international reference changes when other reference instruments with lower uncertainty are developed. 


\section{References}

Gröbner, J. 2012. “A Transfer Standard Radiometer for Atmospheric Longwave Irradiance Measurements." Metrologia 49: S105-11. https://doi.org/10.1088/0026-1394/49/2/S105.

Gröbner, J., I. Reda, S. Wacker, S. Nyeki, K. Behrens, and J. Gorman. 2014. "A New Absolute Reference for Atmospheric Longwave Irradiance Measurements with Traceability to SI Units." Journal of Geophysical Research: Atmospheres 119: 7083-90.

https://doi.org/10.1002/2014JD021630.

Philipona, R., C. Fröhlich, and Ch. Betz. 1995. "Characterization of Pyrgeometers and the Accuracy of Atmospheric Long-Wave Radiation Measurements." Applied Optics 34, no. 9 (March 20): 1598-1605. https://doi.org/10.1364/AO.34.001598.

Reda, I. J. Zeng, J. Scheuch, L. Hanssen, B. Wilthan, D. Myers, and T. Stoffel. 2012. “An Absolute Cavity Pyrgeometer to Measure the Absolute Outdoor Longwave Irradiance with Traceability to International System of Units, SI. Journal of Atmospheric and Solar-Terrestrial Physics 77: 132-43. https://doi.org/10.1016/i.jastp.2011.12.011.

Reda, I., J. R. Hickey, T. Stoffel, and D. Myers. 2002. "Pyrgeometer Calibration at the National Renewable Energy Laboratory (NREL)." Journal of Atmospheric and Solar-Terrestrial Physics 64: $1623-29$. 